See discussions, stats, and author profiles for this publication at: https://www.researchgate.net/publication/41013077

\title{
Attitudes Towards Psychiatry: A Survey of Romanian Medical Residents
}

Article in Academic Psychiatry · January 2010

DOI: 10.1176/appi.ap.34.1.75 · Source: PubMed

CITATIONS

14

3 authors:

Q. Bogdan Voinescu

(3) University Hospitals Bristol NHS Foundation Trust

34 PUBLICATIONS 196 CITATIONS

SEE PROFILE

Andrew N Coogan

National University of Ireland, Maynooth

77 PUBLICATIONS 2,163 CITATIONS

SEE PROFILE
365

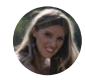

Aurora Szentagotai-Tata

Babeş-Bolyai University

89 PUBLICATIONS 1,127 CITATIONS

SEE PROFILE

Some of the authors of this publication are also working on these related projects:

Project A Computational Distributed System to Support the Treatment of Patients with Major Depression (Help4Mood). View project

Project $\quad$ REBT and CBT in Depression View project 


\title{
Attitudes Towards Psychiatry: A Survey of Romanian Medical Residents
}

\author{
Bogdan I. Voinescu, M.D., M.Sc., Aurora Szentagotai, Ph.D. \\ Andrew Coogan, Ph.D.
}

\begin{abstract}
A ttitudes toward psychiatry affect personnel working in the field and treatment of mentally ill patients (1). Attitudes toward psychiatry as a vocation might primarily affect recruitment, whereas attitudes toward psychiatry patients may affect clinical practice; these issues have not been investigated (2). Doctors' attitudes likely mirror those of the general population, although, unlike the general population, physicians come into contact with psychiatrists and psychiatry patients during their formal training or practice. Thus, a physician may develop a more objective perception of psychiatry than society as a whole. Physicians' opinions are composed of several elements: impressions of psychiatrists themselves, psychiatry patients, and psychiatry as a discipline. Each of these is independent to a degree; one can have a low perception of psychiatry patients but high regard for psychiatrists (2).

There is little research on residents' or specialists' perceptions of psychiatry (2-7). Within the medical community, there is controversy over the role and status of psychiatry, not only among other specialists, but among psychiatrists too (7). A number of published studies tried to assess medical students' perceptions of psychiatry, aiming to counteract the decline of recruitment into psychiatry, although students' preferences were found to be poor predictors of career choice (8). On one hand, some authors state that general opinions of psychiatry are considerably improving, together with its social image $(9-13)$. On the other hand, according to some U.S., U.K., and Australian
\end{abstract}

Received December 8, 2008; revised March 30 and May 24, 2009; accepted June 3, 2009. Dr. Voinescu is affiliated with the Department of Adult Psychiatry at the Clinical County Hospital of Emergency in ClujNapoca, Cluj, Romania; Dr. Szentagotai is affiliated with the Faculty of Psychology at Babes Bolyai University in Cluj-Napoca, CJ, Romania; Dr. Coogan is affiliated with Psychology at National University of Ireland Maynooth in Maynooth, Co. Kildare, Ireland. Address correspondence to Bogdan I. Voinescu, M.D., M.Sc. Clinical County Hospital of Emergency, Psychiatry, V. Babes 43, Cluj-Napoca, Cluj, Romania; b.i.voinescu@swansea.ac.uk (e-mail).

Copyright (C) 2010 Academic Psychiatry studies, the number of students choosing psychiatry as their future specialty has decreased considerably in the last four decades $(3,8,9,14-20)$. Among the possible explanations are psychiatry's low status, low treatment efficacy, lack of scientific support, and frequent criticism by other physicians $(9,18,21)$.

While medical students' attitudes toward psychiatry may influence recruitment, attitudes in trainees and physicians may also influence the ability of doctors to identify, treat, and refer patients with mental disorders. The aim of this study was to evaluate the attitudes of medical residents toward psychiatry and to compare the opinions of residents in psychiatry with those of residents in other specialties. We hypothesized that psychiatric residents would have more favorable attitudes toward their specialty than would residents in other specialties.

\section{Methods}

The study was approved by the Institutional Review Board of Babes-Bolyai University in Cluj-Napoca, Romania. A questionnaire consisting of demographic questions and the Romanian version of the Balon et al. (9) survey was administered to medical residents of various specialties. Participation was voluntary and anonymous and took place online. Invitations explaining the purpose of the study were e-mailed to private message boards used by medical residents. Each item had to be answered for the questionnaire to be validated. Two questionnaires with the same IP address were precluded due to IP address filtering. Completing the survey was considered implied consent to participate in this study.

One hundred twelve residents of various specialties from the main university centers in Romania took part in the survey. More than half $(55 \%, n=62)$ were residents in psychiatry. The majority of residents were women $(80 \%$, $\mathrm{n}=90)$ and were working in Bucharest and Cluj-Napoca 
$(77 \%, n=87)$. About $60 \%$ of respondents $(n=68)$ were in their first 2 years of residency.

A translated version of the questionnaire described by Balon et al. (9) was used. This tool was developed from the Nielsen and Eaton survey (16). It consists of 29 questions that assess attitudes toward the overall merits of psychiatry; its efficacy, role definition, and functioning of psychiatrists; possible abuse and social criticism; career and personal rewards; and specific medical school factors. About half of the questions were stated in terms favorable to psychiatry. All were Likert-type, forced-choice questions scored from 1 (strongly disagree) to 4 (strongly agree), except items 3, 7, 9, 11-14, 16, 18-23, and 29, which were reverse scored. Subtotal and total scores were obtained. We modified item 19 from the Balon et al. (9) survey by omitting "international" from the statement "Psychiatry is a discipline filled with international medical graduates whose skills are of low quality." Internal consistency reliability of the scale was determined by Cronbach alpha (0.557).

To examine the statistical significance of the differences, Student's t test for independent measures was used, with $\mathrm{p}<0.05$ considered significant.

\section{Results}

Most residents agreed that psychiatry is a rapidly expanding, genuine, and valid branch of medicine that has made important progress in curing psychiatric disorders. Psychiatric consultation was assessed to be usually useful. Psychiatrists were seen to have the most authority and influence among health professionals.

Statistically important differences were found between psychiatric residents and residents in other specialties, particularly in career and personal rewards. Most residents thought that psychiatrists earned, on average, as much money as other physicians. Only $19 \%$ of psychiatric residents $(n=12)$ felt that their specialty had a high status among the medical specialties, and $11 \%$ of respondents $(n=7)$ felt that it had high prestige among the general public. Trainees in other specialties had slightly favorable opinions. Most junior doctors in psychiatry $(71 \%, n=44)$ and more than half of those in other specialties $(56 \%$, $\mathrm{n}=28$ ) believed that many trainees who had not been able to obtain a position in other specialties eventually entered psychiatry. About one-half of the young psychiatrists stated that family, friends, or colleagues had discouraged them from entering psychiatry. Of the nonpsychiatric residents, about one-quarter shared these opinions. However,
$52 \%$ of nonpsychiatric residents $(n=26)$ stated that they felt uncomfortable with mentally ill patients. Conversely, $16 \%$ of psychiatric residents $(n=99)$ agreed with this. Half of the psychiatric residents $(52 \%, n=32)$ and $36 \%$ of the other residents $(\mathrm{n}=18)$ considered that showing interest in psychiatry could increase the risk of being seen by others as odd, peculiar, or neurotic. Most of the residents in other specialties $(70 \%, n=35)$ and one-half of those in psychiatry $(n=31)$ thought that the nonpsychiatry and house staff at their medical school respected psychiatry. Table 1 summarizes the main differences between the groups.

\section{Discussion}

Our study is the first of its kind in Romania and tried to determine the attitudes of Romanian resident physicians toward psychiatry, with the aim of uncovering factors that may affect recruitment into psychiatry as a medical specialty, as well as attitudes of health professionals toward psychiatric patients. Attitudes toward psychiatry were moderately positive. We did not find any gender differences in spite of previous results showing that women physicians had more positive attitudes $(4,11,22,23)$. Although psychiatry was perceived to be lower in status than other medical disciplines, it was seen as a rapidly expanding, genuine, and valid branch of medicine that had made important progress in curing major mental disorders. Not long ago, students interested in the psychosocial aspects of medicine and in practicing psychotherapy would have chosen psychiatry; today psychiatrists are more psychopharmacologists $(2,4,9,10,12,19)$. Nevertheless, a lower level of scientific knowledge for admission to psychiatric training is required in some countries (24).

Mental illness is still stigmatized in Romania; a significant proportion of nonpsychiatry doctors agreed that they felt uncomfortable with mentally ill patients, considerably more than of those in similar studies on medical students in the United States or Spain $(9,13)$. Our results revealed a strong perceived discouragement from family, friends, or fellow students of those who chose to specialize in psychiatry. Similarly, a survey of Scottish psychiatrists showed that the perceived low status of their specialty among those in the medical profession and the general public, together with the perception that individuals with psychiatric disorders are difficult to deal with, were core factors thought to influence career choice (3). Health professionals seem to share the stigmatizing attitudes of society toward the mentally ill (regardless of their specialty) 
TABLE 1. Psychiatric Residents' Answers Compared With Those of Other Specialties on Questionnaire Items

\begin{tabular}{|c|c|c|c|c|c|}
\hline Item & Specialty & $\begin{array}{c}\% \\
\text { Agree }\end{array}$ & $\begin{array}{c}\% \\
\text { Disagree }\end{array}$ & $\mathbf{t}$ & $\mathbf{p}$ \\
\hline \multirow{2}{*}{$\begin{array}{l}\text { On average, psychiatrists make as much money as most } \\
\text { other doctors. }\end{array}$} & Psychiatry & 40.3 & 59.6 & -2.033 & 0.044 \\
\hline & Other & 62.0 & 38.0 & & \\
\hline \multirow[t]{2}{*}{ Psychiatry has a low prestige among the general public. } & Psychiatry & 88.7 & 11.3 & 2.869 & 0.005 \\
\hline & Other & 80.0 & 20.0 & & \\
\hline \multirow{2}{*}{$\begin{array}{l}\text { Psychiatry has a high status among other medical } \\
\text { disciplines. }\end{array}$} & Psychiatry & 19.3 & 80.7 & -3.659 & $<0.001$ \\
\hline & Other & 40.0 & 60.0 & & \\
\hline \multirow{2}{*}{$\begin{array}{l}\text { Many people who could not obtain a residency position in } \\
\text { other specialties eventually enter psychiatry. }\end{array}$} & Psychiatry & 71.0 & 29.0 & 2.083 & 0.040 \\
\hline & Other & 56.0 & 44.0 & & \\
\hline \multirow[t]{2}{*}{ My family discouraged me from entering psychiatry. } & Psychiatry & 45.2 & 54.8 & 2.189 & 0.031 \\
\hline & Other & 24.0 & 76.0 & & \\
\hline \multirow{2}{*}{$\begin{array}{l}\text { Friends and fellow students discouraged me from entering } \\
\text { psychiatry. }\end{array}$} & Psychiatry & 46.7 & 53.2 & 2.840 & 0.005 \\
\hline & Other & 24.0 & 76.0 & & \\
\hline \multirow{2}{*}{$\begin{array}{l}\text { If a student expresses interest in psychiatry, he or she risks } \\
\text { being associated with a group of other would-be } \\
\text { psychiatrists who are often seen by others as odd, } \\
\text { peculiar, or neurotic. }\end{array}$} & Psychiatry & 51.6 & 48.4 & 2.462 & 0.015 \\
\hline & Other & 36.0 & 64.0 & & \\
\hline \multirow[t]{2}{*}{ I feel uncomfortable with mentally ill patients. } & Psychiatry & 16.1 & 83.9 & -6.562 & $<0.001$ \\
\hline & Other & 52.0 & 48.0 & & \\
\hline \multirow{2}{*}{$\begin{array}{l}\text { Most nonpsychiatry and house staff at my medical school } \\
\text { are respectful of psychiatry. }\end{array}$} & Psychiatry & 50.0 & 50.0 & -2.452 & 0.016 \\
\hline & Other & 70.0 & 30.0 & & \\
\hline Student's t test, $\mathrm{df}=110$ & & & & & \\
\hline
\end{tabular}

$(1,25)$, but psychiatrists tend to have more favorable attitudes (26). In a study of resident physicians of different specialties, including psychiatry, greater education, additional experience, or choice of specialty did not positively influence attitudes toward mental illness, but having a family member with a psychiatric illness did (27).

In our study, most trainees agreed that those who could not obtain a residency position in other specialties eventually chose psychiatry. In Romania, psychiatry has one of the largest numbers of vacant residency positions and offers significantly better remuneration than most other specialties (it should be mentioned that private health care is still in its infancy in Romania). Emerging questions are whether psychiatrists are physicians deserting other specialties, and if so, what their reasons are.

We did not monitor changes in attitudes during residency, but other studies report that medical students' attitudes modify during medical education $(22,28-31)$, but not during medical practice (4). Due to the small sample size and its heterogeneity, we could not evaluate differences between specific specialties, such as was previously done in finding that the most adverse attitudes come from obstetric-gynecologists and surgeons (4). Further limitations of this study include the small number of participants from a nonrandom sample of junior doctors. Aside from psychiatry, all other specialties were underrepresented. There was also an underrepresentation of male respondents, although this might reflect an increase in the number of women choosing to practice medicine, particularly psychiatry (23). Because the sample responding to the questionnaire was self-selected, it was not possible to calculate a response rate or comment on the characteristics of those who chose not to take part.

The many varied sources of the attitudes assessed in our survey include opinions formed in childhood; during school, college, and university; and in preclinical and clinical training. These attitudes are further influenced by career opportunities, prestige, income, and the conditions of residency (specialization) (32). These attitudes reflect primarily a subjective value system and incomplete and/or misunderstood information. This study is just a step toward clarifying the attitudes of medical health professionals toward psychiatry. 
At the time of submission, the authors declared no competing interests.

\section{References}

1. Royal College of Psychiatrists, Royal College of Physicians of London, British Medical Association: Mental Illness: Stigmatization and Discrimination Within the Medical Profession (Council Report CR91). London: Royal College of Psychiatrists, Royal College of Physicians of London, British Medical Association, 2001

2. Buchanan A, Bhugra D: Attitude of the medical profession to psychiatry. Acta Psychiatr Scand 1992; 85:1-5

3. Brown TM, Addie K, Eagles JM: Recruitment into psychiatry: views of consultants in Scotland. Psychiatr Bull 2007; 31:411-413

4. Baptista T, Pérez CS, Méndez L, et al: The attitudes toward psychiatry of physicians and medical students in Venezuela. Acta Psychiatr Scand 1993; 88:53-59

5. Fogel SP, Sneed JR, Roose SP: Survey of psychiatric treatment among psychiatric residents in Manhattan: evidence of stigma. J Clin Psychiatry 2006; 67:1591-1598

6. Pejovi-Milovancevi M, Leci-Tosevski D, Tenjovi L, et al: Attitudes of psychiatry residents toward mental illness. Medicinski Pregled 2007; 60:382-386

7. Berman I, Merson A, Berman SM, et al: Psychiatrists' attitudes toward psychiatry. Acad Med 1996; 71:110-111

8. Brockington I, Mumford D: Recruitment into psychiatry. Br J Psychiatry 2002; 180:307-312

9. Balon R, Franchini G, Freeman P, et al: Medical students' attitudes and views of psychiatry 15 years later. Acad Psychiatry $1999 ; 23: 30-36$

10. Garyfallos G, Adamopoulou A, Lavrentiadis G, et al: Medical students' attitudes toward psychiatry in Greece. Acad Psychiatry 1998; 22:92-97

11. Maidment R, Livingston G, Katona M, et al: Carry on shrinking: career intentions and attitudes to psychiatry of prospective medical students. Psychiatr Bull 2003; 27:30-32

12. Ndetei DM, Khasakhala L, Ongecha-Owuor F, et al: Attitudes toward psychiatry: a survey of medical students at the University of Nairobi, Kenya. Acad Psychiatry 2008; 32 : 154-159

13. Pailhez G, Bulbena A, Coll J, et al: Attitudes and views on psychiatry: a comparison between Spanish and US medical students. Acad Psychiatry 2005; 29:82-91

14. Goldacre MJ, Turner G, Fazel S, et al: Career choices for psychiatry: national surveys of graduates of 1974-2000 from UK medical schools. Br J Psychiatry 2005; 186:158-164

15. Malhi GS, Parker GB, Parker K, et al: Shrinking away from psychiatry? A survey of Australian medical students' interest in psychiatry. Aus N Z J Psychiatry 2002; 36:416-423

16. Nielsen AC, Eaton JS: Medical students' attitudes about psy- chiatry: implications for psychiatric recruitment. Arch Gen Psychiatry 1981; 38:1144-1154

17. Rajagopal S, Rehill KS, Godfrey E: Psychiatry as a career choice compared with other specialties: a survey of medical students. Psychiatr Bull 2004; 28:444-446

18. Sierles FS, Yager J, Weissman SH: Recruitment of US medical graduates into psychiatry: reasons for optimism, sources of concern. Acad Psychiatry 2003; 27:252-259

19. Syed EU, Siddiqi MN, Imtiaz Dogar, et al: Attitudes of Pakistani medical students towards psychiatry as a prospective career: a survey. Acad Psychiatry 2008; 32:160-164

20. Van Dyke C: Bullish on psychiatry. Acad Psychiatry 2003; 27:235-237

21. Hunt DD, Scott C, Zhong S, et al: Frequency and effect of negative comments ("badmouthing") on medical students' career choices. Acad Med 1996; 71:665-669

22. McParland M, Livingston G, McManus C: The effect of a psychiatric attachment on students' attitudes to and intention to pursue psychiatry as a career. Med Educ 2003; 37:447454

23. Wilson S, Eagles M: The feminization of psychiatry: changing gender balance in the psychiatric workforce. Psychiatr Bull 2006; 30:321-323

24. Søndergård L: Recruitment problems in psychiatry: just a matter of more exposition? Acta Psychiatr Scand 2007; 4:235-237

25. Ucok A, Polat A, Sartorius N, et al: Attitudes of psychiatrists toward patients with schizophrenia. Psychiatry Clin Neurosci 2004; 58:89-91

26. Kingdon D, Sharma T, Hart D: What attitudes do psychiatrists hold towards people with mental illness? Psychiatr Bull 2004; 28:401-406

27. Chin SH, Balon R: Attitudes and perceptions toward depression and schizophrenia among residents in different medical specialties. Acad Psychiatry 2006; 30:262-263

28. Feldmann T: Medical students' attitudes toward psychiatry and mental disorders. Acad Psychiatry 2005; 29:354-356

29. Galka SW, Perkins DV, Butler N, et al: Medical students' attitudes toward mental disorders before and after a psychiatric rotation. Acad Psychiatry 2005; 29:357-361

30. Reddy JP, Tan SMK, Azmi MT, et al: The effect of a clinical posting in psychiatry on the attitudes of medical students towards psychiatry and mental illness in a Malaysian medical school. Ann Acad Med Singapore 2005; 34:505-510

31. Samimi M, Noroozi AR, Mottaghipour Y: The effect of psychiatric clerkship on fifth year medical students' attitudes toward psychiatry and their intention to pursue psychiatry as a career. Iranian J Psychiatry 2006; 1:98-103

32. Kuhnigk O, Strebel B, Schilauske J, et al: Attitudes of medical students towards psychiatry: effects of training, courses in psychiatry, psychiatric experience and gender. Adv Health Sci Educ Theory Pract 2007; 12:87-101 